\section{Inequalities in the Women's Empowerment and their Vulnerability to HIV in India}

\author{
Shri Kant Singh ${ }^{1 *}$, Bhawana Sharma ${ }^{2}$ and Deepanjali Vishwa- \\ karma ${ }^{2}$
}

${ }^{1}$ Department of Mathematical Demography and Statistics, International Institute for Population Sciences, Mumbai, India

${ }^{2}$ International Institute for Population Sciences, Mumbai, India

\begin{abstract}
Background and objectives: Over the years, there has been growing evidence of continuous narrowing gender gap in new HIV infections, despite stagnation in the overall prevalence of HIV in India. Among others, one of the reasons behind the existing pattern in HIVIAIDS in the country is the poor status of women, lack of control over sexuality and poor reproductive and sexual rights among women. NFHS-4 results portray profound increase in woman's status and empowerment in India in the recent years. Therefore, this paper aims to analyze the relationship between woman's empowerment, their HIV vulnerability and prevalence of HIV across different states in India.

Data and methods: This paper utilizes the data from two rounds of National Family Health Surveys, Indian version of Demographic and Health Surveys (DHS) conducted in 2005-06 (NFHS-3) and 2015-16 (NFHS-4) respectively and information collected through National Sentinel Surveillance conducted by National AIDS Control Programme during 2012-2015.

Results: Despite the increase in women empowerment in the recent years, the comprehensive knowledge of HIVIAIDS, a means to reduce women's vulnerability to HIVIAIDS, has not improved significantly. The level of spousal violence has reduced by almost 20 percent in the last one decade (2005-2015) and women participation in household decision making has also increased significantly across different states. Further, there is an extensive awareness among women regarding condom use as a protection against HIV. However, the recent evidence from NFHS 4 and Sentinel Surveillance do not support pronounced association between women's empowerment and consistent condom use visa $V$ is prevalence of HIV, which has been evident in most of sub Saharan African Countries. The relationship seems to be spurious, especially in well-known high HIV prevalence states of India like Andhra Pradesh, Maharashtra, Manipur and Karnataka.
\end{abstract}

*Corresponding author: Shri Kant Singh, Department of Mathematical Demography and Statistics, International Institute for Population Sciences Mumbai, India, Tel: +91 9869229110; E-mail: sksingh31962@gmail.com

Citation: Singh SK, Sharma B, Vishwakarma D (2016) Inequalities in the Women's Empowerment and their Vulnerability to HIV in India. J AIDS Clin Res Sex Transm Dis 3: 007.

Received: April 08, 2016; Accepted: June 06, 2016; Published: June 23, 2016
Conclusions: All programs to curve the pace of HIV epidemic focusing at reducing woman's vulnerability to HIVIAIDS, should not merely focus at general woman's empowerment but there should be specific awareness and capacity building programmes addressing comprehensive knowledge and condom promotion among women. Keywords: Autonomy; Decision making; Empowerment; Estimates; HIV; Knowledge; Violence; Vulnerability

\section{Introduction}

Enhancing empowerment of women is the best strategy and the most effective tool to ensure sustainable development in the world [1]. Women empowerment basically refers to the creation of an environment where women can make independent decisions on their personal development, which leads them to have equal rights in community, society and workplaces [2]. India is mostly known for its cultural heritage, traditions, civilization, religion and geographical features. On the other hand, it is also popular as a male chauvinistic nation [3]. Women in India remained within the four walls of their household, where they totally depended on their counterparts for a long time. After extensive struggle women have been delivered the property rights, voting rights, equality in civil rights before the law in matters of marriage and employment [3]. The fact cannot be denied that women in India have made a considerable progress in almost seven decades of Independence, but they still have to struggle against many handicaps and social evils, which resist the advancement and social up liftment of women folk [4].

\section{Women and HIV Pandemic}

Women are relatively more vulnerable to HIV as they are not only detached from socio-economic opportunities but are denied of access to health care services in many parts of the country [5]. The vulnerability of women can be attributed to a socio-economic and cultural context of India. Women are always susceptible and, therefore, lack awareness in various fields including access and utilization of health care services [5], which has resulted in the growth of women suffering from STI/HIV. According to HIV estimations India [6], HIV prevalence among adults (15-49 years) is estimated at $0.26 \%(0.22 \%-0.32 \%)$ in 2015 . Further, the prevalence of HIV in 2015 among males is estimated at $0.30 \%$ and among females is estimated at $0.22 \%$ in comparison to 2007 which estimated 0.40 among males and 0.26 among females. This confirms a clear decline in the prevalence of HIV nationally but there is narrowing gender gap in the overall prevalence as well as in new HIV diagnosis, which means that the gap of decline in HIV prevalence is less among females comparatively. Data also reveals that women continue to account for more than $40 \%$ of people living with HIV infection in the country [6].

\section{Poverty and HIV}

Economic security is a critical part of women's overall wellbeing including education and health [7]. Poverty includes deprivation, constrained choices, and unfulfilled capabilities, and refers to interrelated features of well-being that impact upon the standard of living and the quality of life [8]. According to World Bank report on confronting AIDS, extensive poverty and unequal distribution of 
income among the gender appears to stimulate the spread of HIV [9]. Further the fourth world conference on women mentioned that among the population living in the world, women in developing countries are the ones who lives in unacceptable conditions of poverty which makes them vulnerable [10]. Women in context of health are considered more vulnerable compared to men because poor women in both rural and urban areas have limited exposure to mass media and less formal education, which also inhibits their access to information [5]. These uneducated and unaware women carry the risk of transmission to their husbands as well as children also [11], which is crucial for the nation to reach the Sustainable Development Goals and end AIDS by 2030 .

\section{Autonomy and HIV}

Autonomy refers to freedom from external control or influence. There have been programs related to women empowerment which provides autonomy to women such as 'National Mission for Empowerment of Women' by Ministry of Women and Child Development in India. It is because of these programs women in India are empowered and now participate in areas such as education, sports, politics, media, art and culture, service sector, science and technology [12]. A study in Brazil revealed that indicators of autonomy that relate to sexuality, mobility and freedom from threat by partners were significantly correlated with practices linked to HIV prevention and with access to health services promoting prevention, especially among young women [13]. Such kind of autonomy is yet to be initiated in India. Though amelioration in the position of women is seen, there is a huge inequality in their empowerment, with tremendous spatial variability in addition to their caste and class. It is against this backdrop, the main objective of this paper is to analyze the inequalities in women's empowerment and their HIV vulnerability, especially in the context of changing prevalence of HIV in the country with focus at continuously narrowing gender gap.

\section{Data and Methodology}

The basic data used in this paper has been taken from two rounds of National Family Health Survey (NFHS), conducted in 2005-2006 and 2015-2016 and National Sentinel Surveillance 2012-2015. Both these surveys have been conducted under the stewardship of Ministry of Health and Family Welfare: Government of India. The International Institute for Population Sciences, Mumbai has been designated as the nodal agency for different rounds of NFHS and ORC Macro, Calverton, Maryland, USA, currently known as the ICF International have been providing the technical support in different rounds of NFHS. On the other hand, National AIDS Control Organization (NACO) has been the nodal agency for conducting Sentinel Surveillance across the country on a continuous basis. The information on different dimensions of inequalities in women's empowerment have been collected from approximately 310,000 women age 15-49, living in 266,000 households across 17 states and UTs in India, which were included in the first phase of NFHS-4. The information on HIV prevalence has been taken from the technical report of HIV estimation and projection based on data collected through Sentinel Surveillance devised to represent the national HIV scenario in India (NACO 2015).

Women's vulnerability to HIV has been assessed through comprehensive knowledge, which describes having correct knowledge of HIV prevention and also rejects two most common misconceptions. These knowledge includes having knowledge that consistent use of condom and having just one uninfected partner limit the risk of getting AIDS, knowledge that a healthy looking person can also have AIDS and rejecting the two most common misconceptions about AIDS transmission (transmission by mosquito bites and by sharing food). The comprehensive knowledge has been taken as a dependent variable to assess the vulnerability with respect to inequality in different dimensions of women's status in India.

The inequality in women's empowerment is computed by using Lieberson's Diversity Index. This index defines the homogeneity and heterogeneity of spatial inequality across different states in India. The index is defined as follows:

If $C_{i}(i=1,2,3, \ldots . n)$ denotes the proportion of individuals in the $i^{\text {th }}$ subclass such that $\Sigma C_{i}=1$, then Lieberson's index of Diversity (D) is defined as

$$
\mathrm{D}=1-\sum^{\mathrm{n}}{ }_{\mathrm{i}}={ }_{1} \mathrm{C}_{\mathrm{i}}^{2}
$$

Theoretically the diversity index varies from 0 to 1 . Zero in case of perfect homogeneity when the inequality is almost nil and one in case of perfect heterogeneity, a case where there is maximum inequality.

\section{Results}

\section{Women's empowerment}

Over the years, the subject of empowerment of women has become a burning issue to ensure their health and wellbeing. The position and status of women all over the world have risen incredibly in the 20th century [12]. According to United Nation Population Information Networks Guidelines, women's empowerment has five components: Women's sense of self-worth; Their right to have and to determine choices; Their right to have access to opportunities and resources; Their right to have the power to control their own lives, both within and outside the home; and Their ability to influence the direction of social change to create a more just social and economic order, nationally and internationally [14]. NFHS-4 has assessed women empowerment by measuring five indicators namely ownership of household assets, women experiencing spousal violence, women's participation in household decision making, having bank account in their name, and having a mobile which they can use on their own.

Table 1 presents the percentage of women owning different household assets namely ownership of house/land, having a bank/saving account and owning a mobile phone. In the context of ownership of house/land by women, Manipur seizes the highest rank (70\%) followed by Bihar (59\%), Meghalaya (57\%) and Tripura (57\%). Similarly, little more than half of women in Karnataka (52\%) and half women in Telangana (50\%) own house/land in their name alone or jointly with other family members. On the other hand, less than half of women in Maharashtra and one-fourth of women in West Bengal and one-fourth of women in Sikkim own a house/land. In case of women having a bank account, more than 80 percent women in Goa and Andaman and Nicobar Islands have their own bank/saving account followed by women in Tamil Nadu (77\%), Puducherry (68\%), Andhra Pradesh (64\%) and Sikkim (60\%). Further, around 50-60 percent of women in Telangana, Karnataka, Tripura and Uttarakhand reported having their own bank/saving account. On the other hand, only a little more than two-fifths of women in Maharashtra and only one-fourth of women in Bihar have their own bank/savings account. In case of ownership of mobile phone, it was found that more than one-fourth of women in all the states and union territories own a mobile phone, which they can use on their own. More than 80 percent of women in Goa and Sikkim followed by a little less than three-fourths 
of women in both Andaman and Nicobar Island and Puducherry own mobile phone. Madhya Pradesh is the only state where less than $30 \%$ of women own a mobile phone.

\begin{tabular}{|c|c|c|c|}
\hline State/UTs & $\begin{array}{c}\text { Owning House } \\
\text { or Land }\end{array}$ & Bank Account & Mobile \\
\hline $\begin{array}{c}\text { Andaman \& Nicobar } \\
\text { Islands }\end{array}$ & 29.7 & 81.8 & 66.9 \\
\hline Andhra Pradesh & 44.7 & 66.3 & 36.2 \\
\hline Bihar & 58.8 & 26.4 & 40.9 \\
\hline Goa & 33.9 & 82.8 & 80.9 \\
\hline Haryana & 35.8 & 45.6 & 50.5 \\
\hline Karnataka & 51.8 & 59.4 & 47.1 \\
\hline Meghalaya & 57.3 & 54.4 & 64.3 \\
\hline Madhya Pradesh & 43.5 & 37.3 & 28.7 \\
\hline Maharashtra & 34.3 & 45.3 & 45.6 \\
\hline Manipur & 68.9 & 34.8 & 63.1 \\
\hline Puducherry & 40.3 & 68.2 & 67.3 \\
\hline Sikkim & 24.8 & 63.5 & 79.8 \\
\hline Telangana & 50.5 & 59.7 & 47.8 \\
\hline Tamil Nadu & 36.2 & 77 & 62 \\
\hline Tripura & 57.3 & 59.2 & 43.9 \\
\hline Uttarakhand & 29.2 & 58.5 & 55.4 \\
\hline West Bengal & 23.8 & 43.5 & 41.9 \\
\hline Percentage & $6 y .5$ & & \\
\hline
\end{tabular}

Table1: Percentage of women by different dimensions of woman's empowerment, measured in terms of ownership of house or land, single or jointly with others, having a separate bank account and mobile phone which they can use on their own in different states/UTs in India, 2015-16.

Spousal violence is a problem that is entrenched in many societies around the world and India is no exception. Although societal awareness and condemnation of the issue have increased in recent years, spousal violence remains a hidden and persistent problem because of the power and control held by the abuse and humiliation suffered by the victims of this crime [15]. Figure 1 portrays a comparative proportion of ever married women experiencing spousal violence in NFHS-3 to NFHS-4. The data reveals that there has been a decline in overall spousal violence in most of the states except for Haryana, Manipur and Meghalaya. Among all the states, the highest decline (around 16\%) in proportion of women experiencing spousal violence is found in Sikkim, Tripura and Bihar. Similarly, the decline in spousal violence of ever-married women is found in states like Uttarakhand by 15 percent, Madhya Pradesh by 12 percent and Maharashtra and West Bengal by less than 10 percent .In contrary, the women experiencing spousal violence has increased by 16 percent in Meghalaya followed by 9 percent in Manipur and 5 percent in Haryana. Though the prevalence is still high but it shows a declining trend in most of the states.

One of the important indicators in measuring empowerment of women is the autonomy of women in decision making both in social and household life [16]. Figure 2 represents the change from NFHS-3 to NFHS-4 in the proportion of women who reported to participate in household decision making. Results reveal that in totality there has been an increase in the participation level at household level by more than three-fourths of women in all the states, except for the state of Haryana and Tamil Nadu. In these two states the participation level at household is found decreasing by 7 and 3 percent point respectively. The proportion of women participating in household level decision making has crossed over 90 percent in states like

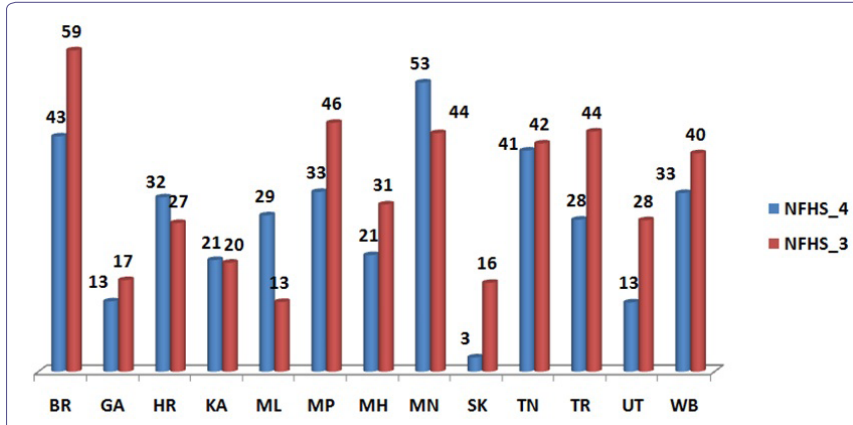

Figure1: Percentage of ever married women who have ever experienced spousal violence (NFHS-3 to NFHS-4).

Sikkim, Goa, Meghalaya, Manipur and Tripura. This shows that these states have a very conducive environment to exercise their reproductive and sexual rights, which may reduce their HIV vulnerability.

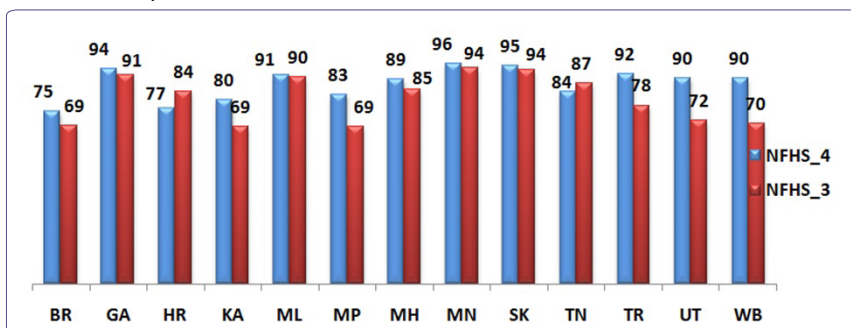

Figure 2: Percentage of married women who participate in household decision-making (NFHS-3 to NFHS-4).

HIV vulnerability: The vulnerability of HIV among women in different states of India has been assessed through their capacity building measured in terms of two indicators namely comprehensive knowledge of HIV/AIDS and consistent condom use as a protection against HIV. Since the beginning of the global HIV epidemic, women have remained at a much higher risk of HIV infection than men in many regions [17]. In some countries, women face significant barriers in accessing healthcare services. This inclines lack of access to comprehensive HIV and Sexual and Reproductive Health (SRH) services, which ultimately leads to incapability of women to control their sexual health and reduce their risk of HIV infection. It is worth mentioning that even in the societies where women are able to access HIV and SRH services, stigma and discrimination against STI/HIV create additional barriers for them to exercise their reproductive and sexual rights [18]. A multi-level analysis of women's empowerment and HIV prevention by reveals that HIV prevalence is positively correlated with indirect indicators of women's empowerment related to their education [19]. Supporting the fact that education plays an important role in HIV prevention, the comprehensive knowledge of HIV/AIDS is being considered in the study.

The most recent evidence on data pertaining to proportion of women having comprehensive knowledge of HIV/AIDS portrays that there is not much improvement in the level of comprehensive knowledge level of HIV/AIDS among adult women age 15-49 in the last one decade i.e., from NFHS-3 to NFHS-4. It is evident from table 2 that less than 30 percent of the women have comprehensive knowledge of HIV/AIDS in states and union territories like Andhra Pradesh, Puducherry, Telangana and Andaman and Nicobar Islands in NFHS-4. Though there has been increase in comprehensive knowledge of HIV/AIDS in Tripura by 10-19 percent point but in 
some states like Goa, Haryana, Meghalaya, Sikkim, Tamil Nadu, Maharashtra and West Bengal, it has increased only by less than 10 percent point. Further, the comprehensive knowledge of HIV/AIDS among women in states like Bihar, Karnataka, Madhya Pradesh, Manipur and Uttarakhand is seen decreasing, which limits the country to reach the Millennium Development Goals despite increasing women's status and empowerment.

\begin{tabular}{|c|c|c|c|c|}
\hline \multirow[t]{2}{*}{ State/UTs } & \multicolumn{2}{|c|}{$\begin{array}{c}\text { Women who have com- } \\
\text { prehensive knowledge } \\
\text { of HIVIAIDS }\end{array}$} & \multicolumn{2}{|c|}{$\begin{array}{l}\text { Women who have } \\
\text { knowledge of consis- } \\
\text { tent condom use }\end{array}$} \\
\hline & NFHS_4 & NFHS_3 & NFHS_4 & NFHS_3 \\
\hline $\begin{array}{l}\text { Andaman \& Nicobar } \\
\text { Islands }\end{array}$ & 29.3 & N.A & 59.5 & N.A \\
\hline Andhra Pradesh & 29.0 & N.A & 57.5 & N.A \\
\hline Bihar & 10.1 & 11.7 & 33.5 & 22.8 \\
\hline Goa & 34.6 & 28.5 & 77.4 & 47.6 \\
\hline Haryana & 31.1 & 24.7 & 71.6 & 46.0 \\
\hline Karnataka & 9.5 & 11.6 & 50.0 & 34.8 \\
\hline Meghalaya & 13.3 & 13.1 & 47.0 & 26.2 \\
\hline Madhya Pradesh & 18.1 & 20.3 & 46.8 & 37.8 \\
\hline Maharashtra & 25.4 & N.A & 72.7 & N.A \\
\hline Manipur & 25.5 & 22.2 & 62.7 & 56.5 \\
\hline Puducherry & 29.5 & N.A & 59.0 & N.A \\
\hline Sikkim & 16.0 & 12.3 & 64.7 & 41.9 \\
\hline Telangana & 28.0 & 11.8 & 57.6 & 41.7 \\
\hline Tamil Nadu & 28.6 & 28.7 & 65.3 & 54.7 \\
\hline Tripura & 18.6 & 9.8 & 53.9 & 30.4 \\
\hline Uttarakhand & 30.0 & 29.5 & 67.9 & 46.9 \\
\hline West Bengal & 40.7 & 44.0 & 79.0 & 79.1 \\
\hline
\end{tabular}

Table 2: Percentage of women who have comprehensive knowledge of HIVIAIDS and knowledge that consistent condom use can protect from HIVIAIDS (NFHS-3 to NFHS-4).

There are a number of factors - Biological, Socio-cultural and Economic which make women more vulnerable to HIV/AIDS. Syndemic risk (which is a function of violence, substance use, perceived financial hardship, emotional distress and self-worth) affects women with and at risk for HIV [20]. Women are twice as likely as men to contract HIV from a single act of unprotected sex [14]. Condom use is a critical element in a comprehensive, effective and sustainable approach to HIV prevention and treatment [21]. Women can play a vital role in the prevention of HIV as it will not only help them in protecting themselves but also their children against it [11]. Therefore, it is important to assess the awareness or knowledge of women regarding consistent condom use as a protection of HIV/AIDS. Last two columns of table 2 represent the change in proportion of women having knowledge that consistent condom use as protection against HIV in NFHS-3 to NFHS-4. The data shows that overall in all the states there is an increasing trend in the awareness level of women regarding condom use as protection against HIV. In some of the states like Goa, Maharashtra and West Bengal, there has been an increase in the awareness level by more than $20 \%$ point followed by an increase in awareness level of women in Meghalaya and Tripura by $10-19 \%$ point. Whereas in states like Bihar, Haryana, Madhya Pradesh, Sikkim, Manipur and Uttarakhand there has been an increase in the awareness level by less than $10 \%$ point among women regarding the knowledge that consistent condom use is a protection against HIV.

\section{Inequality and HIV vulnerabilities}

The inequality in the woman's status has been quantified using Lieberson's Diversity Index, which shows perfect homogeneity as ' 0 ' and perfect heterogeneity as ' 1 ' across different states of India. Different dimensions of woman's empowerment i.e., owning house or land, having a bank account and owning a mobile phone, women experiencing spousal violence and women's participation in household decision making are analysed with respect to comprehensive knowledge of HIV/AIDS, a proxy of woman's vulnerability to HIV/AIDS. The results presented in table 3 reveal high inequality in women empowerment and comprehensive knowledge of HIV/AIDS among different states in India. Further, the data revealed that comprehensive knowledge of HIV is not influenced by women empowerment. Women empowerment itself is not uniformly distributed when ownership of house/land is considered as the inequality varies from 0.38 to 0.98 across different states. In Goa the inequality is low (0.38) but the comprehensive knowledge is relatively high (34.6\%). In contrast there is high inequality in the ownership of house/land of women in the state of Manipur and they also have high comprehensive knowledge about HIV/AIDS. The inequality in terms of women having bank saving account and owning of mobile phone varies across different states except for the state of Sikkim, Tripura and Andaman and Nicobar Island. The data shows that the comprehensive knowledge of women experiencing spousal violence vary a great deal. In the state of Karnataka the inequality is more in context of women experiencing spousal violence and the comprehensive knowledge of HIV/AIDS is also low (9.5\%) among them. The diversity in household decision making clearly shows that in Madhya Pradesh there is high inequality in household decision making and the comprehensive knowledge about HIV/AIDS also tends to be low. Overall, it is found that the different dimensions of women empowerment are not significantly affecting the comprehensive knowledge of HIV/AIDS among women in India.

A combined effect of all these variables on comprehensive knowledge on HIV/AIDS has also been examined through a multiple linear regression equation that is given below, specifying non-significant relation between different dimensions of woman's inequalities $\left(\mathrm{X}_{1}\right.$ to $\left.\mathrm{X}_{5}\right)$ and their HIV vulnerability measured in terms of comprehensive knowledge of $\mathrm{HIV}(\mathrm{Y})$;

$$
\mathrm{Y}=89.1+200.0 \mathrm{X}_{1}+296.1 \mathrm{X}_{2}+399.3 \mathrm{X}_{3}+76.9 \mathrm{X}_{4}-1042.5 \mathrm{X}_{5}
$$

Though the value of unadjusted $\mathrm{R}$ square comes to be 44 percent but the value of adjusted $\mathrm{R}$ square is 13.4 percent with standard error of 8.6. This shows that there is no significant relationship between women empowerment and comprehensive knowledge of HIV/AIDS. That means women empowerment is not significantly affecting the vulnerability of women in terms of comprehensive knowledge of HIV/AIDS in most of Indian states.

\section{Changing HIV scenario in India}

This section focuses on the changing scenario of HIV/AIDS in India, where the trend of prevalence of HIV among adults aged 15-49 is comprehended in four-year time span (2012-2015) from recent HIV estimates derived from the Sentinel Surveillance [6]. The estimate provides a detailed description in what manner the prevalence of HIV in different states of India has changed over the period of time.

According to UNAIDS report India has the third largest HIV epidemic in the world [22]. Though the prevalence of HIV is 
Citation: Singh SK, Sharma B, Vishwakarma D (2016) Inequalities in the Women's Empowerment and their Vulnerability to HIV in India. J AIDS Clin Res Sex Transm Dis 3: 007.

- Page 5 of 7 •

\begin{tabular}{|c|c|c|c|c|c|c|}
\hline State/UT & $\begin{array}{c}\text { Comprehensive } \\
\text { Knowledge }\end{array}$ & $\begin{array}{c}\text { Owning House or } \\
\text { Land }\end{array}$ & Bank Saving Account & Mobile Phone & Spousal Violence & $\begin{array}{c}\text { Household Decision } \\
\text { Making }\end{array}$ \\
\hline $\begin{array}{c}\text { Andaman \& Nicobar } \\
\text { Islands }\end{array}$ & 29.3 & 0.616 & 0.659 & 0.659 & 0.642 & 0.657 \\
\hline Andhra Pradesh & 29.0 & 0.921 & 0.922 & 0.922 & 0.908 & 0.920 \\
\hline Bihar & 10.1 & 0.972 & 0.969 & 0.972 & 0.969 & 0.971 \\
\hline Goa & 34.6 & 0.377 & 0.499 & 0.497 & 0.496 & 0.495 \\
\hline Haryana & 31.1 & 0.946 & 0.948 & 0.952 & 0.94 & 0.950 \\
\hline Karnataka & 9.5 & 0.964 & 0.965 & 0.962 & 0.96 & 0.963 \\
\hline Meghalaya & 13.3 & 0.822 & 0.840 & 0.835 & 0.694 & 0.842 \\
\hline Madhya Pradesh & 18.1 & 0.976 & 0.975 & 0.973 & 0.976 & 0.975 \\
\hline Maharashtra & 30.0 & 0.967 & 0.969 & 0.969 & 0.961 & 0.970 \\
\hline Manipur & 40.7 & 0.877 & 0.867 & 0.866 & 0.903 & 0.865 \\
\hline Puducherry & 25.4 & 0.706 & 0.748 & 0.742 & 0.663 & 0.738 \\
\hline Sikkim & 25.5 & 0.649 & 0.660 & 0.670 & 0.625 & 0.672 \\
\hline Tamil Nadu & 16.0 & 0.964 & 0.968 & 0.968 & 0.971 & 0.967 \\
\hline Tripura & 28.0 & 0.697 & 0.692 & 0.660 & 0.749 & 0.697 \\
\hline Uttarakhand & 28.6 & 0.904 & 0.916 & 0.915 & 0.864 & 0.911 \\
\hline West Bengal & 18.6 & 0.936 & 0.945 & 0.944 & 0.941 & 0.946 \\
\hline
\end{tabular}

Table 3: Women's inequality in empowerment and comprehensive knowledge of HIV/AIDS across different states in India.

lowering in compared to other middle-income countries but because of the large population in India, the prevalence equates to a huge number. Table 4 presents the trend in HIV prevalence among adults aged 15-49 years in different states from 2012 to 2015. The trend of HIV prevalence is found decreasing in almost all the states except for Sikkim and Tripura. Apart from that the prevalence of HIV in the states like Haryana, Meghalaya and Uttarakhand has remained constant all these years. In Karnataka, the HIV prevalence is reduced by $0.6 \%$ followed by Goa where HIV prevalence is reduced by $0.5 \%$ point. In other states like Bihar, Tamil Nadu and West Bengal the reduction in HIV prevalence from 2012 to 2015 is by $0.2 \%$ point and in Madhya Pradesh it is just reduced by $0.1 \%$ in four-year time span. The overall scenario shows that the country is showing a success in responding to HIV epidemic.

\begin{tabular}{|c|c|c|c|c|}
\hline State/UT & $\mathbf{2 0 1 2}$ & $\mathbf{2 0 1 3}$ & $\mathbf{2 0 1 4}$ & $\mathbf{2 0 1 5}$ \\
\hline Andaman \& Nicobar Island & 0.08 & 0.08 & 0.07 & 0.07 \\
\hline Andhra Pradesh & 0.74 & 0.71 & 0.68 & 0.66 \\
\hline Bihar & 0.27 & 0.26 & 0.26 & 0.25 \\
\hline Goa & 0.45 & 0.43 & 0.41 & 0.40 \\
\hline Haryana & 0.13 & 0.13 & 0.13 & 0.13 \\
\hline Karnataka & 0.51 & 0.49 & 0.47 & 0.45 \\
\hline Meghalaya & 0.06 & 0.06 & 0.06 & 0.06 \\
\hline Madhya Pradesh & 0.10 & 0.10 & 0.10 & 0.09 \\
\hline Maharashtra & 0.42 & 0.40 & 0.39 & 0.37 \\
\hline Manipur & 1.45 & 1.34 & 1.24 & 1.15 \\
\hline Sikkim & 0.17 & 0.19 & 0.21 & 0.23 \\
\hline Tamil Nadu & 0.30 & 0.30 & 0.29 & 0.28 \\
\hline Tripura & 0.24 & 0.26 & 0.28 & 0.31 \\
\hline Uttarakhand & 0.11 & 0.11 & 0.11 & 0.11 \\
\hline West Bengal & 0.23 & 0.22 & 0.21 & 0.21 \\
\hline
\end{tabular}

Table 4: Most recent estimates on prevalence of HIV among Adults age 15-49 years in different states/UT in India.

HIV prevalence for Telangana and Puducherry are not available separately.
The overlapping graph reflects the women's autonomy in household decision making and knowledge about consistent condom use, which may be treated as protective factors against their HIV vulnerability among adult women age 15-49 in 15 states of India. Further, it also shows the trend of HIV prevalence in these states as per the recently completed Sentinel Surveillance (2014-15). Figure 3 portrays a contentious relationship between women's autonomy in decision making, awareness to consistent condom use and the prevalence of HIV. There is high level of women's autonomy in household decision making and awareness of consistent condom use as a protection against HIV in states like Haryana and Uttarakhand along with the Andaman and Nicobar Island, which has a negative association with the prevalence of HIV. On the other hand, it is surprising to know that the prevalence of HIV is very high in states like Andhra Pradesh, Maharashtra, Manipur and Karnataka despite women's high level of autonomy in decision making and high awareness regarding consistent condom use as a protection against HIV. But unpredictably in other larger states like Madhya Pradesh, Bihar and West Bengal, the prevalence of HIV maintains to be very low (between 0.09 to $0.25 \%$ ) despite low level of awareness regarding consistent condom use as a protection against HIV (between 34 to $54 \%)$.

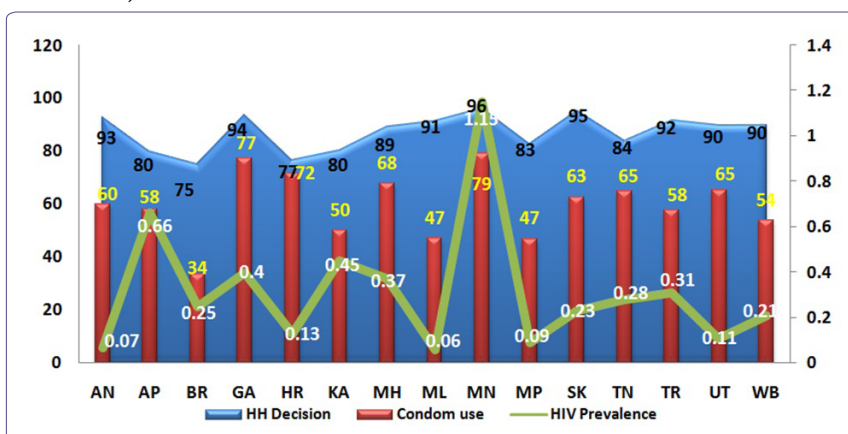

Figure 3: Women's autonomy in decision making, awareness about consistent condom use as a protection against HIV and prevalence of HIV in 15 states and UTs of India. 


\section{Discussion}

Major focus of this paper hinges at the substantial increase in women's autonomy in household decision making and ownership of household assets in the country in the recent years. Increasing women's autonomy has also been responsible for lowered fertility and more positive attitudes toward educating female children [23], which is congruent to the trend of women's participation in overall development process. Furthermore, in almost all the states except in Haryana, Manipur and Meghalaya there is a profound decline of the proportion of ever married women experiencing spousal violence, which has positively impacted the overall health and wellbeing of women in the country. State like Haryana, with skewed sex ratio and higher prevalence of traditional patriarchal norms is expected to have frequent reporting of spousal violence [24]. But it is surprising to find the fact that women in states like Meghalaya, which is a state of matrilineal society, are more likely to experience spousal violence in spite of high women's autonomy. This can be attributed to the fact that since there is a say of women in Meghalaya, hence the reporting must have been higher in comparison to other states in India where women don't open up easily. It can also be possible that the reason for spousal violence could be related to substance abuse and its consequences.

Women's vulnerability to HIV/AIDS may be higher among women from states like Sikkim, Goa and West Bengal, where women's autonomy in decision making has improved considerably but the knowledge about consistent condom use as protection from HIV infection is still low. Similarly, women from Bihar and Meghalaya also lack awareness regarding HIV and its protection despite of high ownership of household assets. The probable reasons might be women are provided with autonomy and technology to some extent but the use of technology for awareness purpose is low. The study by Amin (2003) depicts that awareness messages in India mostly remain neutral in addressing the negative gender and sexual norms fuelling the epidemic. He further argues that most awareness programs scarcely address their risk and need for prevention information. He supports his argument with the following example: Awareness campaigns mainly target high-risk groups to promote and emphasize condom use when practicing high-risk behaviour, but rarely insist that these groups use condom with their wives who remain "uninformed, unaware and unprotected" [16].

Our finding that regardless of decreasing HIV estimates in India, states like Andhra Pradesh, Maharashtra, Manipur and Karnataka are still suffering from high HIV prevalence has also been found in other studies. A recent study by Indian Health Action Trust in 2010, reported that the prevalence of HIV in Maharashtra is high among MSM [25]. So, in Maharashtra the reason for high prevalence might be that HIV exists among MSM (Male having Sex with Male) where female have no role to play. Further, Gregory Armstrong in his study of injecting drug users in North-East [26] found that youth below age of 25 in Manipur is vigorously injecting drugs in their body which might be the cause of high HIV prevalence. The reason for high prevalence of HIV in Andhra Pradesh and Karnataka might be because of unemployment, migration, poor health and unhealthy sexual practices.

Though India has successfully shown progress in halting and reverting the HIV epidemic by expanding treatment, care and support services yet in some states HIV prevalence has been found increasing [6]. As per the report of HIV estimates in India, 2015 it is obvious that the overall trend in HIV prevalence is decreasing but in an account of gender, the prevalence is still high among women. This gives light to the point that there is a lack of comprehensive knowledge about HIV/AIDS and its protection among women especially which is increasing their vulnerability towards HIV.

\section{Conclusion and Recommendations}

A combative relationship has been established between empowerment of women and their vulnerability towards HIV/AIDS. The results have been consistently showing the variations in inequality in women's empowerment across different states in India consequently affecting the comprehensive knowledge of HIV/AIDS. It has been consistent in the results from NFHS-3 to NFHS-4 that those states where there is autonomy provided to women in household decision-making, the incidence of spousal violence has reduced and the awareness about consistent condom use as a protection against HIV has increased. However, change in comprehensive knowledge of HIV/AIDS among women in NFHS-4 is not prominent compared to NFHS-3. The gap between the empowerment of women and knowledge regarding HIV/AIDS is posing a serious threat to the development of the country as a whole because one of the eight-millennium development goals is to combat HIV/AIDS. Lack of awareness can lead to narrowing gender gap in HIV prevalence in India. To achieve this change, it requires policy and programmes that will improve women's access to secure livelihoods and economic resources, alleviate their extreme responsibilities with regard to housework, improve status of women along with decision-making capacity at all levels in all spheres of life, especially in the area of sexuality and reproduction, develop skills in every possible way and raise social awareness through effective programmes of education and mass communication. In addition, issues such as stigma, power/organizational networks and existing norms regarding gender and sexuality should be addressed and a conducive support system and enabling environment should be provided to women.

\section{References}

1. Annan K (2005) Empowering women the most effective development tool. UN News Center, New York, USA

2. Chamar V (2015) Short Essay on Gender Inequality. Social Issues in India, Important India, India.

3. Mondal P (2015) Essay on Women Empowerment in India. Young Article Library 31317.

4. Raju S, Jatrana S (2016) Women workers in Urban India, Cambridge University Press, New Delhi, India.

5. Chatterjee P (1999) The Nation and its Women. In: Chatterjee P (ed.). Partha Chatterjee Omnibus: Comprising Nationalist Thought and the Colonial World, The Nation and its Fragments, and A Possible India, OUP India.

6. NACO, NIMS (2015) India HIV Estimations: Technical Report. Ministry of Health \& Family Welfare Government of India, India.

7. Hess C, Roman S (2016) Poverty, Gender, and Public Policies. Institute for Women's Policy Research, Washington, DC, USA.

8. van Donk M, Msiska R (2002) Conceptual shifts for sound planning: towards an integrated approach to HIVIAIDS and poverty. UNDP, Pretoria, South Africa.

9. The World Bank (1997) Confronting AIDS: public priorities in a global epidemic. Oxford University Press, New York, USA.

10. UN Women, New York, USA UN Women (1995) Fourth World Conference on Women. UN Women, New York, USA.

11. Gill R, Stewart DE (2011) Relevance of gender-sensitive policies and general health indicators to compare the status of South Asian women's health. Womens Health Issues 21: 12-18. 
12. Duhan R (2014) A study of the status of Indian Women under different Legislations. Innovare journal of Social Science. 2: 2.

13. Chacham AS, Maia MB, Greco M, Silva AP, Greco DB (2007) Autonomy and susceptibility to HIVIAIDS among young women living in a slum in Belo Horizonte, Brazil. AIDS Care 19: 12-22.

14. United Nations Population Information Network (POPIN) (2016) Guidelines on Women's Empowerment. United Nations Population Information Network (POPIN), UN Population Division, Department of Economic and Social Affairs, UN Population Fund (UNFPA), New York, USA.

15. Hackett TM (2011) Domestic Violence against Women: Statistical Analysis of Crimes across India. Journal of Comparative Family Studies 42: 267-288.

16. Amin S, Pebley R (1994) Gender Inequality within Households: the Impact of a Women's Development Programme in 36 Bangladeshi Villages. The Bangladesh Development Studies 22: 121-154.

17. UNAIDS (2013) Global Report: UNAIDS report on the global AIDS epidemic UNAIDS, Geneva, Switzerland.

18. Alli F, Maharaj P, Vawda MY (2013) Interpersonal relations between health care workers and young clients: barriers to accessing sexual and reproductive health care. J Community Health 38: 150-155.

19. Greig FE, Koopman C (2003) Multilevel analysis of women's empowerment and HIV prevention: quantitative survey Results from a preliminary study in Botswana. AIDS Behav 7: 195-208.
20. Batchelder AW, Gonzalez JS, Palma A, et al. (2015) A Social Ecological Model of Syndemic Risk affecting Women with and At-Risk for HIV in Impoverished Urban Communities. Am J Community Psychol 56: 229-240.

21. WHO-HIV Department (2015) Global summary of the HIVIAIDS epidemic 2014. World Health Organization HIVIAIDS Department, Geneva, Switzerland.

22. World Economic Forum (2015) Gender Gap Report. World Economic Forum, Geneva, Switzerland.

23. Acharya M, Bennett L (1983) Women and the Subsistence Sector: Economic Participation and Household Decision-making in Nepal. World Bank Staff Working Papers 1: 526

24. NIPCCD (2008) A Socio-Cultural Study of Declining Sex Ratio in Delhi and Haryana: A Report. NIPCCD, New Delhi, India.

25. Ramesh BM, Gaikwad A, Harangule S, Dhamne S (2010) HIVIAIDS Situation and Response in Maharashtra State Report: Epidemiological Appraisal Using Data Triangulation, published by Director, Communications, India Health Action Trust, Bangalore, India.

26. Armstrong G, Nuken A, Medhi GK, Mahanta J, Humtsoe C, et al. (2014) Injecting drug use in Manipur and Nagaland, Northeast India: injecting and sexual risk behaviours across age groups. Harm Reduct J 11: 27. 